Perspective

\title{
Stoicism and death acceptance: integrating Stoic philosophy in cognitive behaviour therapy for death anxiety
}

\author{
Rachel E. Menzies ${ }^{1} \cdot$ Lachlan F. Whittle ${ }^{1}$ \\ Received: 26 October 2021 / Accepted: 13 January 2022 \\ Published online: 03 February 2022 \\ (c) The Author(s) 2022 OPEN
}

\begin{abstract}
Growing empirical evidence has revealed the central role of death anxiety in numerous mental health conditions. Given this, there is a significant need for treatments which specifically address fears of death. Whilst such treatments have only recently been developed within clinical psychology, the discipline of philosophy has a long history of offering valuable perspectives on death which may ameliorate this fear. In particular, we propose that the philosophy of Stoicism, which originated in ancient Greece and influenced the early development of cognitive and behaviour therapy (CBT), is of particular benefit to clinicians seeking to address death anxiety. We present a summary of Stoic philosophy and its arguments concerning death. Through integrating the ideas of Stoicism, we argue that current treatments for death anxiety would benefit from directly integrating Stoic perspectives on death. Lastly, we review evidence which suggests that cultivating attitudes to death which are consistent with Stoic philosophy may be associated with reduced death anxiety. We conclude that an awareness of Stoic philosophy has the potential to guide and improve CBT treatments for fears of death. Further research is needed in order to confirm whether treatments centering on Stoic perspectives on death lead to significant reductions in death anxiety.
\end{abstract}

Keywords Death anxiety ·Transdiagnostic · Existential · CBT · Philosophy · Stoicism

\section{Death anxiety as transdiagnostic construct}

Fears of death are a universal part of the human experience, featuring across our species' recorded history for at least the last four thousand years [1]. Whilst some individuals may develop effective coping strategies to mitigate this fear, for others, the dread of death may result in immense distress and maladaptive defense mechanisms [2]. Further, death anxiety has been argued to be a transdiagnostic construct, underpinning a range of mental health conditions [3]. In support of this argument, death anxiety has been shown to predict the symptom severity of at least twelve different mental illnesses, including depressive disorders, anxiety-related disorders, and addictive disorders [4]. Further, experimental evidence has highlighted the causal role of death anxiety in numerous conditions. Studies have demonstrated that reminders of death increase compulsive washing in obsessive-compulsive disorder (OCD) [5], bodily checking, threat perception and reassurance seeking in panic disorder, illness anxiety, and somatic symptom disorder [6], avoidance in social anxiety and specific phobias [7], and disordered eating behaviours among women [8].

Despite the central role of death anxiety in several mental health conditions, it has been argued that standard treatments do not typically address the underlying fears of death [3]. Instead, treatments focus on disputing the client's

Rachel E. Menzies, rachel.menzies@sydney.edu.au | 'School of Psychology, Brennan MacCallum Building (A18), The University of Sydney, Sydney, NSW 2006, Australia. 
probability estimates of various causes of death. For example, cognitive and behaviour therapy (CBT) traditionally seeks to provide corrective information on the likelihood of a heart attack in panic disorder [9], of contracting an illness in OCD [10], or of falling to one's death in specific phobias [11]. Such treatments may fail to address the underlying fear of death, therefore contributing to the "revolving door" phenomena in clinical settings, in which a client may experience successful treatment for one disorder, only to return to treatment later in life with a different disorder [3, p. 590].

Given this, it is essential to develop novel treatments which specifically target death anxiety. However, few studies have examined treatment efficacy for death anxiety. A meta-analysis by Menzies et al. [12] identified just 15 randomised controlled trials which measured death anxiety as an outcome. Findings revealed that CBT produced significant reductions in fears of death, in comparison to other therapies. However, only five studies using CBT for death anxiety were identified in this meta-analysis, and of these, only one study was conducted within the last three decades. These studies also primarily centred on graded exposure (i.e., gradually and systematically facing a feared place or situation, such as a funeral home or cemetery), with a notable absence of cognitive therapy interventions for death anxiety. Clearly, there is a dire need for effective and novel therapeutic approaches to reduce fears of death. In particular, there has been surprisingly little discussion of cognitive approaches to death anxiety.

\section{The role of philosophy in clinical psychology}

Whilst death anxiety is only beginning to be recognised as a transdiagnostic construct, death has been considered by psychologists since the field's earliest days. William James, often credited as the founder of American psychology, stated that knowledge of the inevitability of death is the "worm at the core" of human experience [13, p. 119]. These problems do of course have a much longer history. Struggles with fears of death have been prevalent for thousands of years and discussed at length, often predating scientific and empirical practice. A lack of empiricism, however, is not equivalent to a lack of academic rigour, which can be seen, for example, within the schools of traditional philosophy in which these topics have been deeply contemplated for millennia. Looking towards philosophy as a resource can provide practitioners with the opportunity to combine cutting edge theory and approaches with the thousands of years of heavy lifting already undertaken by some of history's brightest minds.

Philosophy has played a clear and present role within psychology, with research and practice being actively shaped by the epistemologies of practitioners, whether that be introspectionism, behaviourism, or humanism. Wilhelm Wundt, for example, is credited with separating psychology from philosophy and developing psychology into an experimental and empirical field [14], with this separation only occurring little over a century ago. However, there have been far more recent and direct incorporations of philosophy within psychology, with much of modern cognitive-behavioural theory finding its roots within traditional philosophies [15]. Most overtly, this is seen in the development of psychotherapies based upon pre-existing schools of philosophy. For example, mindfulness-based therapies, such as mindfulness-based stress reduction (MBSR) and mindfulness-based cognitive therapy (MBCT) have been gathering increasing empirical support, whilst being directly inspired by, and deeply steeped in Buddhist philosophies $[16,17]$. Another example can be found in existential psychotherapy, which adheres to the tradition of existential philosophy in confronting challenging questions on death and meaning, whilst intending to be incorporated within larger schools of therapy, such as CBT [18].

\section{An introduction to Stoicism}

Due to the breadth of traditional philosophy, there are many schools within philosophy which have been underutilised within clinical psychology, one of these being the school of Stoicism. The origins of Stoicism trace back to ancient Greece and to a philosopher named Zeno. Sadly, none of his writings have survived beyond fragments, but what was left to us was the outline of a philosophy which centres itself around peace of mind. Continuing in the Greek tradition to the slaveturned-philosopher Epictetus, we find that the Stoic approach to philosophy was considered to be a practical discipline. One of the key tenants of Stoicism associated with Epictetus is the recognition of oneself as "accountable only for what is subject to your control" $[19,1.12 .32]$. This extends to accepting that the things which "lie outside the sphere of choice are neither good nor bad" $[19,2.13 .10]$, meaning that one should seek to be indifferent to things outside of one's control, including the opinions, judgements or emotions of others, and the advent of tragedies or unwanted circumstances. This teaching is intended to be directly applied, with a specific intended application being addressing one's anxiety. 
The contents of this belief system are also often identified with the works of its most popular Roman practitioners: Seneca, a powerful statesman and advisor to a young Emperor Nero, and Emperor Marcus Aurelius, the fifth and final of the Five Good Emperors of Rome. Another of the core tenets of Stoicism, as expressed by Aurelius, lies in acknowledging that experiencing hardships is inevitable but that if one's "distress has some external cause, it is not the thing itself that troubles you, but your own judgement of it - and you can erase this immediately" [20, 8.47]. This recognition of distress, and emotions in general, as purely internal and therefore controllable is key to the Stoic philosophy.

Both of the tenants stated above lay emphasis on one's judgements, what we today would refer to as value judgements or cognitions [21]. In combining these two tenants we can identify the argument that one should resist in passing judgements on the things outside of one's control (as Epictetus advised above), as these judgements serve no purpose yet can cause a person harm, and cultivate indifference to things which are not within one's complete control. Controlling one's judgements, and emotions by extension, is certainly easier said than done, but Stoicism provides the application of reason and rational argument to dismiss irrational ways of thinking as the method through which this can be achieved. In one such application, Seneca discusses fear and anxiety as being due to "projecting our thoughts far ahead of us instead of adapting ourselves to the present." [22, Epistle 5.8], this being identified as irrational due to our inability to act on or control the future. With this, Seneca provides a way of thinking and a shift in focus which can aid in addressing these painful emotions.

\subsection{The history of Stoicism in cognitive behaviour therapy (CBT)}

The Stoic approach towards cognitions should immediately draw comparisons to modern CBT [23]. In fact, direct comparisons have been made, for example, between Stoic approaches to maladaptive thoughts and Beck's concept of cognitive distancing [21]. These similarities are no coincidence, with Aaron Beck and Albert Ellis, both progenitors of the cognitivebehavioural movement, writing extensively on the origins of their therapies (cognitive therapy and rational-emotive behaviour therapy (REBT), respectively) stemming from Stoicism [21]. Ellis, in his original works outlining and defending REBT, goes so far as to directly quote Epictetus, stating that Stoic tenants underpinned his theories and practice [24]. The fact that Stoic philosophy is built into the foundations of CBT is rarely recognised by practitioners. This is an issue, as a failure to interact with this rich source material risks impeding the potential improvement of these therapies [25].

It should also be clarified that an adaptation of a philosophy to clinical practice does not require practitioners to adhere to each and every tenant of them, with Ellis [24] also clarifying that there are aspects of Stoicism which were not included or directly relevant to his purposes. This point serves to demonstrate that once clinicians are informed regarding a philosophy, they are then free to tool these philosophies to purpose. When it comes to philosophies as broad and deep as Stoicism, adaptation becomes essential. This is not always a straightforward task, however isolating the most relevant aspects of a philosophy can be made far simpler if this is done with a particular topic for application in mind. For Stoicism, a prime candidate for such a topic is death anxiety.

\subsection{The relevance of death anxiety to Stoicism}

Death was a far more present danger in the ancient world, with significantly lower life expectancies, a high prevalence of diseases, and frequent wars, all of which would be concerns for Stoic philosophers and their audiences. Another concern particular to philosophers and statesmen was the popular punishment of forced suicide which was handed out to high-ranking officials, this eventually coming to include Seneca himself [22]. Stoicism was often presented and directly intended to address worries surrounding death, with the ancient Stoics writing extensively on the subject. This is because mortality exemplifies Stoic teachings on control and emotion, as death involves painful and extreme emotions, whilst simultaneously being completely inevitable and therefore outside of one's control. Whilst the Stoics often would discuss misfortunes in more abstract terms, death and the fear of death were mentioned overtly ("I can't escape death; but is it beyond my power to escape the fear of death...?" $[19,1.27 .9-10]$ with overcoming this fear being seen as essential to living a good life ("He lives badly who does not know how to die well"; [26]). The Stoics proposed multiple arguments and lines of reasoning to contest with fears of death, including presenting death as a natural part of life; as being no different to the changes one sees around them and have already experienced; as fair due its inevitability to all without discrimination; and as serving as a reminder that one is still living and therefore able to act. This reconceptualization of death as something undeserving of fear, and thoughts of death as being tools for positive change is powerful, can be adapted to clinical practice, and tailored to those who need assistance in resolving their dread of death. 


\section{Integrating Stoicism in CBT for death anxiety}

As discussed, a central principle of both Stoicism and CBT is the idea that it is our beliefs and interpretations that are the cause of anxiety. Interestingly, in illustrating this point, the Stoics frequently used death as an example. In the words of the former slave Epictetus:

It is not things themselves that trouble people, but their opinions about things. Death, for instance, is nothing terrible (otherwise it would have appeared that way to Socrates as well), but the terrible thing is the opinion that death is terrible. [27, Chapter 5]

Notably, this notion is supported empirically. Recent research has found a significant positive correlation between maladaptive cognitions about death, and anxious affect surrounding death [28]. Introducing this idea early in therapy is therefore crucial, to allow the individual to see that it is their maladaptive beliefs which are contributing to their anxiety about death, rather than death being inherently unpleasant. In doing so, the clinician can lay the groundwork for integrating Stoic lines of argument (such as those outlined below), in order to challenge the client's specific beliefs and fears about death.

\subsection{Non-existence and the 'symmetry argument'}

Whilst the experience of death anxiety can be highly variable, for many individuals their fear centers on the idea of nonexistence. That is, the notion of no longer being able to think, feel, or experience any sensation, and the knowledge that life will go on for others after one's own death, can be sources of much anxiety. To counter this, some Stoics highlight the unknowability of death as a justification for the irrationality of fearing it. For example, Seneca writes: "You fear death, but your fear is only of a rumor, and what could be more foolish than a man who's afraid of words?" [22Epistle 91.19]. He therefore argues that it is pointless to spend one's life fearing something that one has not actually experienced prior, given this fear must therefore be based on (potentially erroneous) assumptions about the future.

While this approach has some clinical value, other lines of Stoic argument propose the opposite, arguing instead that the non-existence which follows death is indeed something we have all experienced. This is known as the 'symmetry argument', first proposed by the philosophical school known as Epicureanism, and encouraged by the existential psychotherapist Yalom [2] to address individuals' dread of non-existence. A central teaching of Epicurus, the school's founder, was that "Death is nothing to us", because "what has been dissolved has no sensation, and what has no sensation is nothing to us" [29, Kyria Doxa 2]. That is, death brings with it the inability to experience any pain, and therefore, death cannot be painful or distressing. Later Epicureans extended this argument further, encouraging us to:

Look back at the eternity that passed before we were born, and mark how utterly it counts to us as nothing. This is

a mirror that Nature holds up to us, in which we may see the time that shall be after we are dead. [30, 3.972-974]

That is, we have all previously experienced the state of non-existence prior to being born; we are not troubled by the fact that for thousands of years we did not think, feel, or experience anything. Echoing this teaching, gravestones in ancient Rome belonging to followers of Epicurus were often engraved with the epitah: "Non fui, fui, non sum, non curo" ("I was not; I was; I am not; I don't care"; [31, p. 60]).

Whilst this idea was first developed in the Epicurean school, Stoics such as Seneca read Epicurus' works and, where relevant, incorporated his ideas into their practice of Stoicism. The symmetry argument is one such example. In a letter to the bereaved Marcia following the death of her son, Seneca reminds her that death:"returns us to that peace in which we reposed before we were born. If someone pities the dead, let him also pity those not yet born" [32]. He emphasises this idea again in another letter:

Wouldn't a man seem to you the greatest of all fools, if he wept because for a thousand years previously, he had not been alive? He's just as great a fool if he weeps because he won't live for a thousand years to come. [22, Epistle 77.11]

Introducing the symmetry argument, and Stoic writings on it, may help ameliorate fears of non-existence by normalising it as something the individual has previously experienced, and which has not caused them distress. 


\subsection{Death as natural and universal}

The Stoic indifference to death stemmed in large part from their acceptance of death as natural and universal. "Do not despise death", Aurelius insists, "Welcome it, rather, as one further part of nature's will" [20,9.3]. If death is part of "nature's will", the Stoics argued, it makes no more sense to fear it than it does to fear the falling of leaves in autumn, or new growth in spring. In a similar vein, the Stoics viewed death as a precondition for life, pointing out that life without death is simply impossible. In Seneca's words: "Whoever doesn't want to die, doesn't want to live. Life is granted with death as its limitation; it's the universal endpoint... and who can complain of sharing a condition that no one does not share?" [22, Epistle 30.10-11].

Inherent to this idea is the universality of death, as it is something all humans will experience. In his Meditations, a collection of personal reflections written without any intention of publication, Aurelius instructs himself to "Think constantly of all the sorts of men, of various professions and of all the nations on earth, who have died", before proceeding to list by name great leaders and thinkers who are now deceased, to re-iterate the universality of death [20, 6.47]. This exercise may also prove a useful therapeutic tool. For example, like Aurelius, the client may be encouraged to write a list of people who have died, including loved ones, distant acquaintances, or well-known figures. They may also be guided to consider the fact that 108 billion people have already died [33], and that around 111 people worldwide die each minute [34]. Such tasks seek to normalise death, and to help the individual see themselves as one person in a chain of billions who will temporarily get to experience existence.

\subsection{Perspectives on the shortness of life}

Individuals with death anxiety often hold beliefs about life being too short. Counter to this view, the Stoics frequently argued that the exact length of one's life is in fact unimportant; rather, it is the quality of that life that matters. Seneca writes:

This desire for life must be knocked out of us. We must learn that it makes no difference when you undergo the thing that must be undergone some time or other; that it matters how well you live, not how long. [22, Epistle 101.15]

In particular, one must accept the shortness of life because it is something that one cannot completely control. Thus, clients should be guided to cultivate Stoic indifference to the length of time they or their loved ones will live. Some individuals will believe that they can indeed have control over their own lifespan, and may view their maladaptive behaviours (e.g., compulsive washing, avoiding leaving the home, excessive exercise, or frequenting medical services) as a way of doing so. However, contrary to this view, meta-analytic research has shown that individuals with clinical anxiety do not live longer relative to controls [35]. Similarly, one study of over three million people revealed that not one anxiety disorder examined appeared able to reduce the risk of death from either natural (e.g., illness) or unnatural causes (e.g., accidents), compared to people without anxiety disorders [36]. Thus, for clients who hold this view, therapy may help the client understand that although these anxious behaviours may in theory ward off one particular cause of death (e.g., compulsive checking of a stove may reduce the chance of death by household fire), they are unlikely to actually extend a person's lifespan.

In addition to accepting one's lifespan as outside of their control, clients should be encouraged to cultivate gratitude for the time that they do have. This sentiment is captured in Aurelius' words: "Mortal man, you have lived as a citizen in this great city. What matter if that life is five or fifty years?" [20, 12.36]. To cultivate a sense of gratitude, one valuable exercise may include researching the lifespans of other animals. Comparing the length of time one has already lived to the lifespan of animals such as the mayfly, which lives for less than a day, can provide a more balanced perspective. A similar approach may involve considering the average lifespan of earlier humans. At the time the Stoics were writing, for example, the average life expectancy in the Roman empire was just over 20 years. In fact, $50 \%$ of infants born in Rome would die before they reached ten years old [37]. Even as recently as 150 years ago, the average life expectancy in the United States of America was just 45 years [38].

Extending the Stoic idea further, therapy may seek to encourage gratitude for ever coming into existence at all. As Richard Dawkins persuasively argues "We are going to die, and that makes us the lucky ones", because each of us have "won the lottery of birth against all odds" [39, p. 1]. That is, the chance of our own unique DNA sequence ever 
being created at all as less than one in a billion. In line with this argument, Menzies [40] suggests that clients calculate the probability of their own birth, such as by tracing their family history and estimating the probability of their own parents ever meeting, followed by their grandparents, and so on. Thus, for clients who believe that life is too short, cognitive approaches should seek to cultivating gratitude for, and acceptance of, however many years one is allotted.

\subsection{The value of preparing for death}

The Stoics also encouraged the practice of "futurorum malorum præmeditatio" (commonly referred to by modern Stoic authors as "negative visualisation"), as a means of overcoming anxiety about feared outcomes. Negative visualisation consists of vividly imagining an unwanted future scenario, to prepare oneself for this outcome. They encouraged visualising all manner of events which the individual is averse to, including illness, poverty, loss of reputation, and the loss of loved ones. Whilst the Stoics encouraged people to prepare for all feared outcomes, they particularly emphasised the importance of continuously reminding oneself of death. In Seneca's words: "Study death always, so that you'll fear it never" [22, Epistle 30.18].

The practice of negative visualisation overlaps strikingly with the contemporary CBT technique of imaginal exposure therapy (i.e., repeatedly imagining a feared situation in a prolonged and deliberate manner in order to reduce anxiety). Current treatment approaches for death anxiety include imaginal exposure for the death of a loved one, or for one's own death, such as in the form of a writing a detailed 'illness story' (e.g., Furer and Walker [41]). Meta-analytic evidence also supports the value of this practice for ameliorating fears of death. In a meta-analysis by Menzies et al. [12] exposure therapy (including imaginal exposure) was found to produce significant reductions in death anxiety, and outperformed other therapy modalities.

Drawing from Stoic philosophy encourages us to take the principles of exposure therapy one step further. In addition to traditional, structured exposure therapy exercises, a Stoic approach prioritises reminding ourselves of death far more frequently. Aurelius writes extensively about this strategy, and encourages himself to remember death at all times, in order to cultivate moral and mindful behaviour: "You may leave this life at any moment: have this possibility in your mind in all that you do or say or think" $[20,2.11]$. Inherent in this idea is the notion that one is still living, and therefore, has the potential to act. In another passage of Meditations, Aurelius recounts that "Epictetus used to say that when you kiss your child you should say to yourself: 'Tomorrow you may be dead"' [20, 11.34]. While this idea may appear grim, reminding oneself of this fact would likely help in cultivating acceptance of mortality, and encourage gratitude for the time one does have with loved ones.

Similarly, accepting death is seen by the Stoics as the key step to creating joy and contentment. Only by truly accepting death, can we be free from fear. In Seneca's words: "Life cannot be free from worry for any man who thinks too much about extending it...Make your life joyful by putting aside all your anxiety about keeping it" [22, Epistle 4.4-6]. This idea may be particularly relevant to clients with anxiety-related disorders, whose behaviours often reflect maladaptive attempts to extend life, as discussed. These individuals may be encouraged to consider the impact of their anxious behaviours on their quality of life, particularly given the aforementioned research which indicates that anxious individuals do not in fact succeed at outliving their non-anxious counterparts.

In line with the Stoic argument about preparing for death, Menzies and Veale [42] encourage the use of daily death reminders, such as through keeping images or symbols of death and impermanence (e.g., a skull or hourglass) in one's environment. Doing so may help to cultivate acceptance of death, and reduction of anxiety in response to reminders of death. Technology can also assist with this task. For example, apps such as WeCroak and Kick the Bucket provide daily reminders of mortality through a push notification on your phone's home screen. Individuals may also consider changing their ringtone to a song with themes of death (e.g.,'Don't Fear the Reaper' by Blue Öyster Cult, or 'All Things Must Pass' by George Harrison), or changing their phone screen background to an image which serves a similar purpose.

\section{Evidence for Stoicism and reduced death anxiety}

Despite the theoretical relevance of Stoicism to reduced fears of death, there is only preliminary evidence for the potential benefit of treatments incorporating Stoic principles. Only one study has explicitly assessed the relationship between Stoic attitudes to death and death anxiety. French et al. [43] measured 'Stoicism' using two items which assessed: (1) the level of comfort with the knowledge of one's own mortality, and (2) the degree to which one was raised with an awareness that life is finite. High levels of Stoicism were found to significantly predict lower levels of death anxiety. Stoicism also 
predicted more variance in death anxiety than did age, a well-established predictor of fears of death [44, 45], and spirituality. The authors concluded that cultivating cognitions associated with Stoicism may be a valuable target for intervention. However, the use of this brief two-item measure, and its lack of direct relevance to principles of Stoic philosophy, make it difficult to draw strong conclusions regarding the relationship between Stoic attitudes and death anxiety.

\subsection{Neutral acceptance}

Whilst no other study has directly examined Stoicism, the Stoic attitude to death overlaps heavily with a well-researched construct known as 'neutral acceptance'. Wong et al. [46] have previously established three types of acceptance of death: escape acceptance (i.e., accepting death because it is viewed as an escape from one's present pain or suffering), approach acceptance (i.e., accepting death because it is viewed as a gateway to a better life, such as being reunited with loved ones in an afterlife) and neutral acceptance (i.e., accepting death because it is viewed as an unavoidable and natural part of life). On Wong et al.'s [46] Death Attitude Profile-Revised (DAP-R), neutral acceptance is captured by items such as "I would neither welcome death nor fear it", "Death is neither good nor bad", and "Death is a natural aspect of life", which overlap closely with Stoic perspectives on death.

Notably, whilst all three types of acceptance are associated with reduced death anxiety, neutral acceptance has been shown to be most protective [46]. Neutral acceptance of death is negatively correlated with fears of death and death avoidance, both in the general community [47-49] and in medical professionals [49, 50]. Similarly, nurses who score high on neutral acceptance have been shown to have more positive attitudes towards caring for the dying [47]. Neutral acceptance is also positively correlated with indifference towards death [46], and a more positive image of death in young people [51,52]. Individuals who score high on neutral acceptance also have more negative views on life extension (i.e., attempts to extend life and fight dying through whatever means available, a concept which overlaps with the aforementioned maladaptive attempts to extend life found in many anxiety-related disorders) [53].

In addition to being reliably associated with reduced death anxiety, neutral acceptance of death also predicts improved mental health more broadly. For example, greater neutral acceptance of death is positively associated with psychological and physical wellbeing [46], distress tolerance [54], and meaning in life [48] and negatively associated with anger [54] and depression [46]. Notably, in contrast to escape and approach acceptance, only neutral acceptance is significantly associated with better psychological and physical wellbeing, as well as reduced depression [46]. That is, accepting death as a natural and unchangeable part of life is associated with better wellbeing and mood than accepting death as either a gateway to an afterlife, or an escape from one's suffering.

\subsection{Experimental evidence for treatment components integrating Stoicism}

These cross-sectional findings suggest that a Stoic acceptance of death appears beneficial for death anxiety and mental health more broadly. In line with this, treatments which seek to cultivate Stoic acceptance may potentially ameliorate death anxiety. However, no studies have explicitly examined this possibility. To the best of our knowledge, only one study has explicitly included Stoic philosophy in an intervention targeting death anxiety. Menzies et al. [55] developed an online CBT-based program, Overcome Death Anxiety (ODA), to specifically address fears of death. ODA integrates treatment approaches including cognitive therapy and exposure therapy for death anxiety. Although the program does not include a specific module on Stoicism, central ideas taken directly from the philosophy are scattered throughout the program. For example, on the first page of the ODA program, users are introduced to two quotes from Seneca and Marcus Aurelius. Further, at two separate points during the ODA program, users are presented with additional Stoic quotes as "reflection tasks", which they must write a response to, before being able to proceed to the next section. During ODA, users also watch a video explaining philosophical perspectives on death, which includes discussion of the Stoic approach to death.

ODA also integrates the central principle of Stoicism in its module focusing on cognitive therapy. In the "Challenging Your Thinking" module, users are presented with five unhelpful beliefs about death they have endorsed. For each of these beliefs, they are prompted to respond to the question: "Are you worrying about an outcome that you can't control? Is there any point to this type of worry?". Thus, for each negative belief about death the user has identified, they are prompted to consider whether this feared outcome is within, or outside of, their control, in line with Stoic principles. To offer corrective feedback, users are also provided with a sample answer to this question, developed by the clinicians, for each of their thoughts. For example, one user endorsed the belief: "If a loved one were to die suddenly, it would destroy me." In response to the questions above, the user responded: "There is no point worrying about it as it is inevitable and 
it is something I cannot control. It's better to enjoy the moments with our loved ones rather than dread a moment that will happen regardless".

Preliminary findings indicate that the program produced a significant improvement in death anxiety [56]. In a Phase I trial of the program among 20 individuals with mental health diagnoses, $60 \%$ of those who completed post-treatment questionnaires had made a reliable change in their overall death anxiety on the Collett-Lester Fear of Death Scale-Revised. This program does serve to demonstrate that Stoic principles can be effectively integrated within clinical interventions. However, further research is needed to clarify which components of the program contribute to this reduction. For example, it is possible that it was the modules centring on exposure therapy, rather than those focusing on cognitive therapy, which led to these improvements.

\section{Conclusion}

Mounting evidence suggests the transdiagnostic role of death anxiety, with growing calls for novel treatment approaches to specifically target this fear. In this regard, clinical psychology can benefit from drawing on approaches to death outlined by the Stoic philosophers. In particular, CBT interventions which are informed by Stoicism should seek to: (1) emphasise the importance of beliefs about death in driving death anxiety, (2) encourage acceptance of death as natural, universal, and outside of one's control, (3) cultivate acceptance of, and gratitude for, one's lifespan, and (4) emphasise the value in preparing for death.

In line with this, reading further into Stoic approaches to death may be beneficial for both clients and therapists alike. For example, How to Die: An Ancient Guide to the End of Life [57] is an accessible collection of writings about death by the Stoic philosopher Seneca. For more contemporary summaries of Stoicism, A Guide to the Good Life: The Ancient Art of Stoic Joy [58], and The Daily Stoic [59] each contain a section on Stoic approaches to death. The original Stoic texts (including Seneca's Letters from a Stoic [22] and Aurelius'Meditations [20]) can serve as surprisingly palatable introductions to these ideas, and are often freely available online.

Cross-sectional evidence suggests a relationship between Stoic attitudes to death (e.g., neutral acceptance) and reduced death anxiety. Further, preliminary evidence suggests that a CBT-based treatment which integrates Stoic perspectives on death appears to reduce fears of death. Future studies are needed to investigate whether: (1) interventions which center on Stoic philosophy can significantly reduce death anxiety, (2) complementing existing CBT treatments with a component on Stoic approaches to death can have an additive effect on death anxiety, and (3) increasing death acceptance (through interventions informed by Stoicism) may improve broader mental health and wellbeing, consistent with theoretical arguments [60].

Authors' contributions RM conceptualised the article. Both LW and RM contributed to the original draft of the manuscript. RM led the review and editing of the manuscript. Both authors read and approved the final manuscript.

Funding This research received no specific Grant from any funding agency, commercial or not-for-profit sectors.

Data availability Not applicable.

Code availability Not applicable.

Declarations

Competing interests The authors declare no competing interests.

Open Access This article is licensed under a Creative Commons Attribution 4.0 International License, which permits use, sharing, adaptation, distribution and reproduction in any medium or format, as long as you give appropriate credit to the original author(s) and the source, provide a link to the Creative Commons licence, and indicate if changes were made. The images or other third party material in this article are included in the article's Creative Commons licence, unless indicated otherwise in a credit line to the material. If material is not included in the article's Creative Commons licence and your intended use is not permitted by statutory regulation or exceeds the permitted use, you will need to obtain permission directly from the copyright holder. To view a copy of this licence, visit http://creativecommons.org/licenses/by/4.0/. 


\section{References}

1. Menzies RE, Menzies RG. Mortals: how the fear of death shaped human society. Sydney: Allen \& Unwin; 2021.

2. Yalom ID. Staring at the sun: overcoming the terror of death. San Francisco: Jossey-Bass; 2008.

3. Iverach L, Menzies RG, Menzies RE. Death anxiety and its role in psychopathology: reviewing the status of a transdiagnostic construct. Clin Psychol Rev. 2014;34:580-93. https://doi.org/10.1016/j.cpr.2014.09.002.

4. Menzies RE, Sharpe L, Dar-Nimrod I. The relationship between death anxiety and severity of mental illnesses. Br J Clin Psychol. 2019;58(4):452-67. https://doi.org/10.1111/bjc.12229.

5. Menzies RE, Dar-Nimrod I. Death anxiety and its relationship with obsessive-compulsive disorder. J Abnorm Psychol. 2017;126(4):36777. https://doi.org/10.1037/abn0000263.

6. Menzies RE, Sharpe L, Dar-Nimrod I. The effect of mortality salience on bodily scanning behaviours in anxiety-related disorders. J Abnorm Psychol. 2021;130(2):141-51. https://doi.org/10.1037/abn0000577.

7. Strachan E, Schimel J, Arndt J, Williams T, Solomon S, Pyszczynski T, Greenberg J. Terror mismanagement: evidence that mortality salience exacerbates phobic and compulsive behaviours. Pers Soc Psychol Bull. 2007;33:1137-51. https://doi.org/10.1177/01461 67207303018.

8. Goldenberg JL, Arndt J, Hart J, Brown M. Dying to be thin: The effects of mortality salience and body mass index on restricted eating among women. Pers Soc Psychol Bull. 2005;31(10):1400-12. https://doi.org/10.1177/0146167205277207.

9. Hackmann A. Panic disorder and agoraphobia. In: Bennett-Levy J, Butler G, Fennell M, Hackman A, Mueller M, Westbrook D, editors. Oxford guide to behavioural experiments in cognitive therapy. Oxford: Oxford University Press; 2004. p. 59-80.

10. Vaccaro LD, Jones MK, Menzies RG, Wootton BM. Danger ideation reduction therapy for obsessive-compulsive checking: preliminary findings. Cogn Behav Ther. 2010;29(4):293-301. https://doi.org/10.1080/16506073.2010.512643.

11. Kirk J, Rouf K. Specific phobias. In: Bennett-Levy J, Butler G, Fennell M, Hackman A, Mueller M, Westbrook D, editors. Oxford guide to behavioural experiments in cognitive therapy. Oxford: Oxford University Press; 2004. p. 161-71. https://doi.org/10.1093/med:psych/ 9780198529163.001 .0001$.

12. Menzies RE, Zuccala M, Sharpe L, Dar-Nimrod I. The effects of psychosocial interventions on death anxiety: a meta-analysis and systematic review of randomised controlled trials. J Anxiety Disord. 2018;59:64-73. https://doi.org/10.1016/j.janxdis.2018.09.004.

13. James W. Varieties of religious experience. Cambridge: Harvard University Press; 1985.

14. Farr RM. Wilhelm Wundt (1832-1920) and the origins of psychology as an experimental and social science. Br J Soc Psychol. 1983;22(4):289301. https://doi.org/10.1111/j.2044-8309.1983.tb00596.x.

15. Edward M, Kim D. The philosophical foundations of cognitive behavioral therapy: Stoicism, Buddhism, Taoism, and Existentialism. J Cogn Behav Psychother. 2015;15(1):37-50.

16. Chiesa A, Malinowski P. Mindfulness-based approaches: are they all the same? J Clin Psychol. 2011;67(4):404-24. https://doi.org/10.1002/ jclp.20776.

17. Keng SL, Smoski MJ, Robins CJ. Effects of mindfulness on psychological health: a review of empirical studies. Clin Psychol Rev. 2011;31(6):1041-56. https://doi.org/10.1016/j.cpr.2011.04.006.

18. Yalom ID, May R. Existential psychotherapy. In:Wedding D, Corsini RJ, editors. Current psychotherapies. Boston: Cengage Learning; 2018. p. 273-307.

19. Hard R. Epictetus: discourses, fragments, handbook (Trans.). Oxford: Oxford University Press; 2014.

20. Aurelius M. Meditations (M Hammond, Trans.). London: Penguin Classics; 2006.

21. Robertson D. The philosophy of cognitive-behavioural therapy (CBT). Milton Park: Routledge; 2018. https://doi.org/10.4324/97804 29482748

22. Seneca LA. Letters from a Stoic (R. Campbell, Trans.). London: Penguin Classics; 2014.

23. Seligman M. Agency in Greco-Roman philosophy. J Posit Psychol. 2021;16(1):1-10. https://doi.org/10.1080/17439760.2020.1832250.

24. Ellis A. Is rational-emotive therapy Stoical, Humanistic, or spiritual? J Humanist Psychol. 1979;19(3):89-92. https://doi.org/10.1177/00221 6787901900314.

25. Rhodes P, Conti J. Why clinical psychologists should read philosophy: an introduction. Aust Clin Psychol. 2016;2(1):805.

26. Seneca LA. On serenity of mind, 11.4. How to die: an ancient guide to the end of life (J. Romm, Trans.). Princeton: Princeton University Press; 2018.

27. Long AA. Epictetus: Encheiridion. How to be free: an ancient guide to the Stoic life (Trans.). Princeton: Princeton University Press; 2018.

28. Menzies RE, Sharpe L, Dar-Nimrod I. The development and validation of the Death Anxiety Beliefs and Behaviours Scale (DABBS). 2022 (Under review).

29. Warren J. Lucretius, symmetry arguments, and fearing death. Phronesis. 2001;46(4):466-91. https://doi.org/10.1163/156852801753736 508.

30. Lucretius T. On the nature of things (A. E. Stallings, Trans.). London: Penguin Classics; 2007.

31. Carroll M. Vox tua nempe mea est. Dialogues with the dead in Roman funerary commemoration. Accord Res Pap. 2008;11:37-80.

32. Seneca LA. To Marcia, 21 (J. Romm, Trans.). In: Romm J, editor. How to die: an ancient guide to the end of life. Princeton University Press: Princeton; 2018.

33. Kaneda T, Greenbaum C, Kline K. 2020 World Population Data Sheet. Washington, DC: Population Reference Bureau; 2020.

34. United Nations, Department of Economic and Social Affairs, Population Division. World population prospects: the 2019 revision, DVD edition. 2019. https://population.un.org/wpp2019/Download/Standard/Mortality/. Accessed 26 Oct 2021.

35. Miloyan B, Bulley A, Bandeen-Roche K, Eaton WW, Gonçalves-Bradley DC. Anxiety disorders and all-cause mortality: systematic review and meta-analysis. Soc Psychiatry Psychiatr Epidemiol. 2016;51:1467-75. https://doi.org/10.1007/s00127-016-1284-6.

36. Meier SM, Mattheisen M, Mors O, Mortensen PB, Laursen TM, Penninx BW. Increased mortality among people with anxiety disorders: total population study. Br J Psychiatry. 2016;209:216-21. https://doi.org/10.1192/bjp.bp.115.171975.

37. Saller RP. Patriarchy, property, and death in the Roman family. Cambridge: Cambridge University Press; 1997. 
38. Riley JC. Estimates of regional and global life expectancy, 1800-2001. Popul Dev Rev. 2005;31(3):537-43. https://doi.org/10.1111/j.17284457.2005.00083.x.

39. Dawkins R. Unweaving the rainbow. Dublin: Houghton Mifflin; 1998.

40. Menzies RG. The dread of death and its role in psychopathology. Queensland: Paper presented at the 35th National Conference of the Australian Association for Cognitive and Behaviour Therapy; 2012.

41. Furer P, Walker JR. Death anxiety: a cognitive-behavioral approach. J Cogn Psychother. 2008;22(2):167-82. https://doi.org/10.1891/08898391.22.2.167.

42. Menzies RE, Veale D. Creative approaches to treating the dread of death. In: Menzies RG, Menzies RE, Dingle G, editors. Existential concerns and cognitive-behavioral procedures: an integrative approach to mental health. Springer Nature: Switzerland; 2021.

43. French C, Greenauer N, Mello C. A multifactorial approach to predicting death anxiety: assessing the role of religiosity, susceptibility to mortality cues, and individual differences. J Soc Work End Life Palliat Care. 2017;13(2-3):151-72. https://doi.org/10.1080/15524256.2017. 1331181.

44. Henrie J, Patrick JH. Religiousness, religious doubt, and death anxiety. Int J Aging Hum Dev. 2014;78:203-27. https://doi.org/10.2190/AG. 78.3.a.

45. Wink P, Scott J. Does religiousness buffer against the fear of death and dying in late adulthood? Findings from a longitudinal study. J Gerentol. 2005;60(4):207-14. https://doi.org/10.1093/geronb/60.4.P207.

46. Wong PTP, Reker GT, Gesser G. Death attitude profile-revised: a multidimensional measure of attitudes toward death. In: Neimeyer RA, editor. Death anxiety handbook: research, instrumentation, and application. Washington, DC: Taylor \& Francis; 1994. p. 121-48.

47. Clements R, Rooda LA. Factor structure, reliability, and validity of the death attitude profile-revised. OMEGA. 2000;40(3):453-63. https:// doi.org/10.2190/XFF0-C6UA-58PC-PHPB.

48. Tomer A, Eliason G. Beliefs about self, life, and death: testing aspects of a comprehensive model of death anxiety and death attitudes. In: Tomer A, editor. Death attitudes and the older adult. Philadelphia: Taylor \& Francis; 2000. p. 137-53.

49. Peters L, Cant R, Payne S, O'Connor M, McDermott F, Hood K, Morphet J, Shimoinaba K. Emergency and palliative care nurses' levels of anxiety about death and coping with death: a questionnaire survey. Australas Emerg Nurs J. 2013;16:152-9. https://doi.org/10.1016/j. aenj.2013.08.001.

50. Jansen J, Schulz-Quach C, Eisenbeck N, Carreno DF, Schmitz A, Fountain R, Franz M, Schäfer R, Wong PTP, Fetz K. German version of the death attitudes profile-revised (DAP-GR) - translation and validation of a multidimensional measurement of attitudes towards death. BMC Psychol. 2019. https://doi.org/10.1186/s40359-019-0336-6.

51. López-Pérez ME, Pino-Juste M, Campos A. Image of death and attitude towards death. N Am J Psychol. 2020;22(4):701-10.

52. López-Pérez ME, Pino-Juste M, Campos A. Mental imagery and anxiety toward death in adolescents. Death Stud. 2020. https://doi.org/ 10.1080/07481187.2020.1864683.

53. Barnett MD, De La Garza JD. Attitude toward death, not religious commitment mediates the relationship between political ideology and attitudes toward life extension. Death Stud. 2021. https://doi.org/10.1080/07481187.2021.1944402.

54. Esnaashari F, Kargar FR. The relation between death attitude and distress: tolerance, aggression, and anger. OMEGA. 2018;77(2):154-72. https://doi.org/10.1177/0030222815593871.

55. Menzies RE, Sharpe L, Helgadóttir FD, Dar-Nimrod I. Overcome death anxiety: the development of an online CBT program for fears of death. Behav Chang. 2021. https://doi.org/10.1017/bec.2021.14.

56. Menzies RE, Julien A, Sharpe L, Menzies RG, Helgadóttir FD, Dar-Nimrod I. Overcoming death anxiety: a phase I trial of an online program in a clinical sample. 2022 (Under review).

57. Seneca LA. How to die: an ancient guide to the end of life (J. Romm, Trans.). Princeton: Princeton University Press; 2018.

58. Irvine WB. A guide to the good life: the ancient art of Stoic joy. USA: Oxford University Press; 2009.

59. Holiday R, Hanselman S. The daily Stoic. NY: Penguin Putnam Inc.; 2016.

60. Wong PTP, Tomer A. Beyond terror and denial: the positive psychology of death acceptance. Death Stud. 2011;35(2):99-106. https://doi. org/10.1080/07481187.2011.535377.

Publisher's Note Springer Nature remains neutral with regard to jurisdictional claims in published maps and institutional affiliations. 